\title{
The Synthesis of the Arts: From Ceremonial Ritual to "Total Work of Art"
}

\author{
Steven Brown ${ }^{1 *}$ and Ellen Dissanayake ${ }^{2}$ \\ ${ }^{1}$ Department of Psychology, Neuroscience \& Behaviour, McMaster University, Hamilton, ON, Canada, ${ }^{2}$ School of Music, \\ University of Washington, Seattle, WA, United States
}

The nineteenth century notion of a Gesamtkunstwerk or "total work of art" referred to a performance spectacle that synthesized multiple forms of the arts into a unified work, often times taking place in a grand setting that befit the spectacle. Such a performance would be a quasi-religious ceremony occurring in a location akin to a temple. We argue here that, long before aesthetic theorists devised the notion of a total work of art, religious ceremonies themselves showed all of the key features of a Gesamtkunstwerk. In fact, we propose that ceremonial rituals are essentially assemblages of arts-related behaviors and objects, and that this observation provides the historical and cognitive underpinnings for what would later become the total work of art in aesthetic practice. An important implication of this argument is that religion and the arts co-evolved during the course of human history.

OPEN ACCESS

Edited by: Susanne Huber, Universität Wien, Austria

Reviewed by:

Raquel Andrade Weiss, Federal University of Rio Grande do

Sul (UFRGS), Brazil Richard Parncutt,

University of Graz, Austria

*Correspondence:

Steven Brown

stebro@mcmaster.ca

Specialty section: This article was submitted to Evolutionary Sociology and Biosociology

a section of the journal

Frontiers in Sociology

Received: 26 February 2018 Accepted: 27 April 2018 Published: 15 May 2018

Citation:

Brown S and Dissanayake E (2018) The Synthesis of the Arts: From Ceremonial Ritual to "Total Work of

Art". Front. Sociol. 3:9.

doi: $10.3389 /$ fsoc. 2018.00009

\section{Keywords: arts, ritual, religion, ceremonies, human evolution, Gesamtkunstwerk}

\section{THE "TOTAL WORK OF ART"}

The notion of a Gesamtkunstwerk (GKW) or "total work of art" was established by aesthetic philosophers and practitioners in the nineteenth century. It represented a grand unification of the arts, encompassing theater, music, dance, and visual design, as applied to transcendent literary themes from mythology, folklore, history, and religion. Richard Wagner's music-dramas, most notably Parsifal, represent a significant manifestation of this philosophy in action. The concept of a GKW extended to architecture, such that Wagner's operas were to be performed in a newly constructed venue that would provide the requisite religious feel of a performance occurring in a shrine, a veritable temple of the arts. This place, located in the small German town of Bayreuth, was called a festival house, reminiscent of the pagan festivals that characterized Germany's ancient past. As with a festival, audience members would engage in a pilgrimage to attend these opera performances. All in all, the GKW would achieve an aesthetic synthesis-or what Smith (2007) calls a "pseudo-organic totality"-that would create a utopian feeling of spiritual purification for those in attendance, hailing back to Romanticist aspirations for a life grounded in aesthetics.

This philosophy permeated artistic and architectural practice well into the twentieth century and even into modern times. Smith's (2007) historical analysis of the Gesamtkunstwerk includes the "total theater" of the Bauhaus movement, the folk spectacles and propaganda films of Nazi Germany, magical theme parks such as Disneyland, Andy Warhol's multimedia Happenings, the pseudo-organic totality of the internet with its potential for collaborative networking, and the multimedia immersiveness of virtual reality. As Smith writes, "the total work of art is still a potent aesthetic idea, always intertwined with technology, continuing to blur distinctions between high and mass culture, artwork and commodity spectacle" (Smith, 2007, p. 6). The total work of art is 
not merely a synthesis of artistic media per se, but is often times a form of mass spectacle that engenders total immersion, social collectivity, and even spiritual redemption by those who experience it.

We will argue in this paper that, long before European aesthetic theorists had devised the notion of a GKW, ceremonial rituals in indigenous cultures had for millennia been syntheses of the arts on a similar scale and of a similar scope to GKW's. This has been well-described from the perspective of the anthropology of the arts (Durkheim, 1912/1995; Turner, 1966; Schechner, 1974, 1985; Tambiah, 1979; Dissanayake, 1988, 2017; Rappaport, 1999). Our primary thesis here is that the GKW concept has deep evolutionarily-predisposed and anthropological roots, and that the ethnographic "ceremony-as-Gesamtkunstwerk" is the ancient precursor of the more recent practice of "Gesamtkunstwerkas-ceremony." Our second thesis focuses on religious practice itself, and argues that ceremonial rituals across cultures can be accurately and productively described as collections of arts behaviors and objects. If one performed a thought experiment and eliminated, one by one, each art behavior or object from any particular ceremonial ritual, there would be little that would remain. From this notion, we propose that religious practice and the arts co-evolved, to the point that one system could not have emerged in human societies without the other. We justify this by arguing that the arts function to provide an emotionally-felt and transcendent means of establishing contact with supernatural beings during communal ceremonial rituals.

Before discussing these issues, we first explore an important cognitive question: how do the arts combine? In other words, if someone had the intention of creating a total work of art, how would they go about doing it? For this, we need to think about the nature of the arts and how artforms can combine with one another. We will first discuss how to construct a GKW, and then look for historical precedents of the GKW in ceremonial rituals.

\section{HOW THE ARTS COMBINE: A FRAMEWORK FOR SYNTHESIZING THE ARTS}

In order to think about how to create a synthesis of the arts, we need to consider what the arts are and how they can be synthesized. For the purposes of this article, we conceive of the arts in terms of the standard conception of "branches" found in the humanities, with the four major branches being music, dance, theater ${ }^{1}$ (and film, but also including oral forms of storytelling and poetry), and the visual arts, as shown by the tetrad in Figure 1. (We ignore arts related to the chemical senses,

\footnotetext{
${ }^{1}$ We are using the term "theater" here to signify narrative artforms that are expressed through either acting or storytelling. While acting is always performative, storytelling can be done in either a performative manner (oral forms of storytelling and poetry) or, in literate societies, in a written-hence nonperformative-manner. This creates a complication for our scheme. Technically speaking, written literature belongs together with the visual arts, since written text is a type of two-dimensional image (Elkins, 1999). While we acknowledge this complication in classifying written forms of narrative in our scheme, we will not deal any further with this issue in the current article.
}

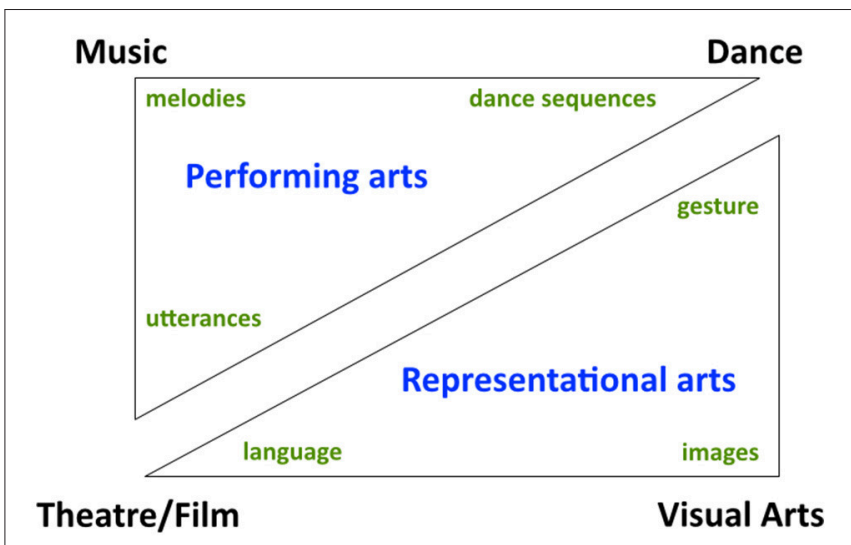

FIGURE 1 | A classification of the arts. The figure shows the four major branches of the arts as making up a tetrad. Within that are opposing triangles. The top triangle is made up of the performing arts. These arts are phrase-based, as comprised of verbal utterances (or sentences in written forms), melodies, or dance sequences. The bottom triangle is made up of the representational arts, which comprise a "narrative triad" of spoken language, gesture, and graphic images. Theater/film and dance sit in both categories.

such as perfumery and gastronomy). We next divide the tetrad into two opposing triangles based on cognitive and behavioral considerations. The top triangle comprises the "performing arts," and therefore excludes the visual arts as static objects, such as paintings and sculptures. The bottom triangle comprises what we refer to as the "representational arts", since they can be used in a narrative fashion to referentially convey information about objects, people, and events. Music is excluded from this grouping since it is generally unable to convey information referentially in the way that a sentence or picture easily can. It is not critical for this scheme that all forms of dance or visual art be representational. What is important is that these artforms have the potential to be representational and that this is a critical feature that distinguishes them from music. Note that, in the double-triangle representation, theater/film and dance sit in both categories.

As indicated inside the top triangle in Figure 1, the three performing arts are all based on the domain-specific generation of phrases. These phrases include verbal utterances for theater/film (and sentences in written literature), melodies for music, and dance sequences for dance. In all cases, phrase formation is guided by what theorists in each domain refer to as a grammar or syntax. The notion of musical syntax is quite prominent in the field of music psychology (Patel, 2008), while that of dance syntax is present, though less prominent, in the analysis of dance (Kimmel and Preuschl, 2016). Next, it is noted inside the bottom triangle that the three representational artforms embody, respectively, the three principal modalities of representation in human cognition, namely spoken language, gesture, and image making. In other words, each of the representational arts is specifically dedicated to conveying narrative via one of the three modalities of narrative representation in human cognition, highlighting the strong linkage between the arts and cognition. This creates three 
parallel channels for the conveyance of narrative ideas via spoken language, gesture, and graphic images, respectively, something we can think of as a "narrative triad" (Yuan et al., in press). In addition, language itself can be conveyed multimodally through speech (theater and storytelling), writing (literature), and gesture (sign language, pantomime, emblematic gestures). As we describe below in the section "Ceremonial Rituals as Total Works of Art," the experience of these artforms, both individually and through their combinations, engenders strong emotional effects on producers and perceivers, resulting in a process of group emotional expression during both religious and secular contexts (von Scheve and Salmella, 2014).

How do the arts combine to create syntheses? Figure 2 starts with the same double-triangle representation as Figure 1, but now includes additional information related to how the arts are able to combine to create synthetic forms. The four branches of the arts have the potential for six binary interactions, each of which we now describe.

\section{Music/Theater Interaction}

There are at least five major manners by which music can combine with language and theatrical narratives. The first is a direct coupling between musical pitches and spoken syllables via the singing of words. Compositionally, this can be achieved by either adding text to an existing melody or by setting an existing text to music, the latter process referred to as text setting. Note that the text can resemble standard speech (akin to a play) or can be much closer to poetic text, as in many art songs. In addition, the singing of words can occur in wholly sung works like opera, or it can occur in alternation with spoken segments, as in musical theater, vaudeville, opéra comique, and Singspiel. Second, music videos contain the singing of words, but couple that to visual narratives, in almost all cases occurring in the absence of speech or dialogue. Third, in much cinema-but in very little theater-background music (so-called underscore) is played during the dialogue and action of the film. This is a much looser type of music/narrative coupling than that between pitch and syllable during singing. Fourth, in the case of incidental music, music is performed between the scenes of a play, with wellknown examples being Mendelssohn's music for Shakespeare's A Midsummer Night's Dream and Grieg's music for Ibsen's Peer Gynt. Finally, "program music" refers to instrumental musical works composed in such a manner as to map onto the plot line of literary or theatrical works, as is seen in Dvorak's Noonday Witch or Tchaikovsky's Romeo and Juliet overture.

\section{Dance/Music Interaction}

Dance is universally performed to music, including rhythmicbased percussion music; the only real exceptions are some forms of modernist dance in Western cultures that have no musical accompaniment. The dance/music interaction can occur in three major manners. First, dance can be performed so as to conform to the meter of the music being played, as in a waltz or tango. Hence, the dance will be choreographed such that the largest and strongest movements occur in synchrony with the strong beats of the music, resulting in a parallel metrical structure between the dance and the music. In addition to dance itself, a similar type of movement/music interaction is found in certain forms of puppet theater, such as Vietnamese water puppetry. Second, dance can occur without consideration for musical beats. In this case, the music plays "in the background," and the choreography occurs relatively independent of it. There are many prominent examples in world cultures, especially in narrative forms of dance. Dances can, of course, employ both types of coupling, synchronizing to musical beats during some dance segments, but not in others. Finally, in some forms of contemporary dance, composers can create music for pre-choreographed dance works, hence showing the reverse progression to dance being choreographed to music.

\section{Dance/Theater Interaction}

There are two major manners by which dance interacts with theater. First, dance can itself be a type of theater. This is seen especially in the case of narrative forms such as ballet, where dancers portray characters and interact with one another just as dramatic characters do, but in the absence of speech. For example, Prokofieff's ballet Romeo and Juliet is a danced and unspoken version of the Shakespeare play, using exactly the same characters and narrative events as the theatrical version. Second, in the case of dramatic works, dance can be interleaved with non-dance segments of the work. On the one hand, this can occur in completely sung works, such as opera, where the dancing occurs to an instrumental musical accompaniment, typically in the absence of singing. Well-known examples are found in the operas of the Baroque period (e.g., the works of Lully, Rameau, and Gluck), where ballet segments are interleaved with the sung segments of the opera. In such forms, the singers are almost never the same people as the dancers. Next, dance segments can be found in spoken dramatic works, the major example being musical theater. As with opera, dance segments are typically interleaved with the verbal part of the work, rather than occurring simultaneously with it. This is, at least in part, an accommodation to the fact that it is physically challenging to sing and dance at the same time, although pop singers since the time of Madonna and Michael Jackson have managed to achieve this in a compelling fashion, creating the three-way interaction between sentences/utterances, melodies, and dance sequences. In musical theater, unlike opera, the singers very often perform the dance segments as well, accompanied by a corps of dancers who also make up the musical chorus, as in musicals like Oklahoma and West Side Story.

\section{Theater/Visual Arts Interaction}

Because we conceive of the visual arts as being comprised of static objects-aside from some avant garde works of the twentieth and twenty-first centuries described below-the major interaction between the visual arts and performing artforms such as theater is found in the static components of theatrical works. This includes the sets, props, costumes, and make-up. It also includes the architectural features that make up the performance venue, including its interior and exterior design. Another interaction that we list in the figure is comprised of films that occur as part of multimedia video installations in art museums. While some of the works are stand-alone videos, others are components of larger installation works that contain static (or even mobile) visual-art 


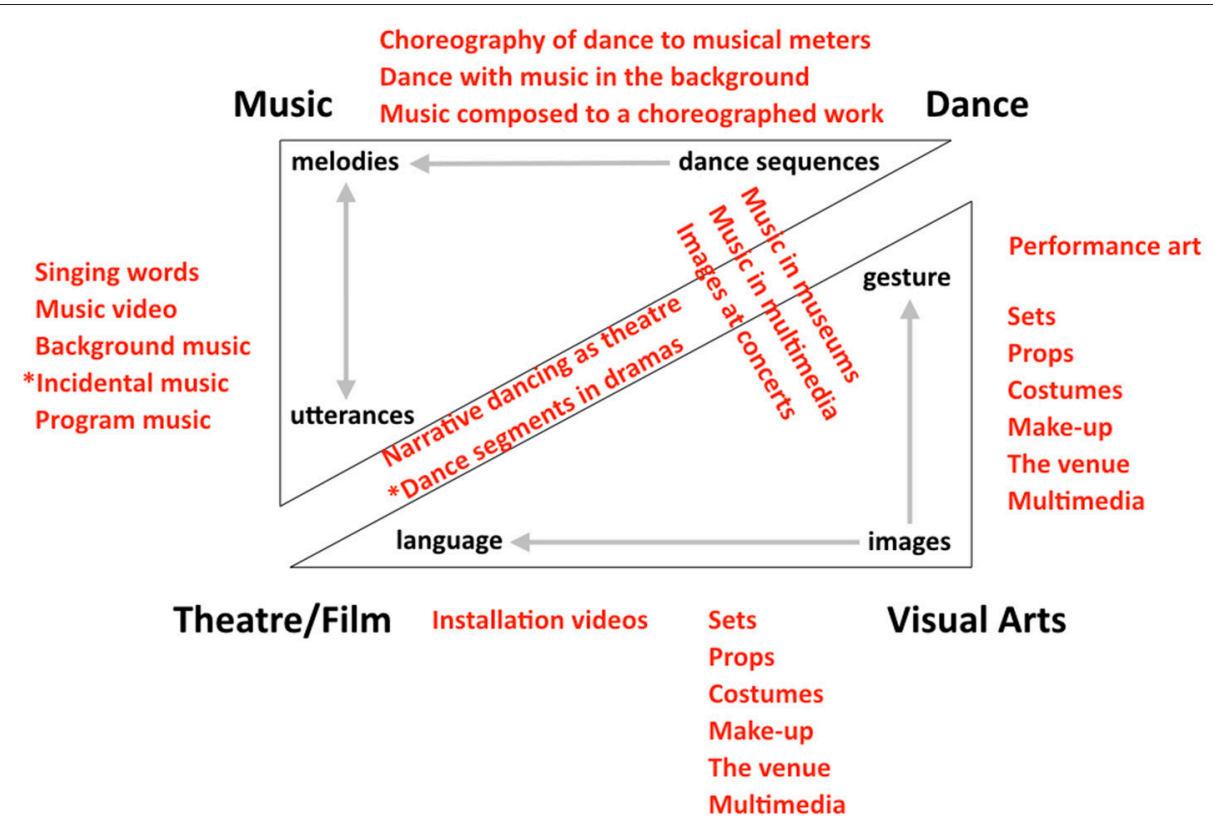

FIGURE 2 | Interactions among the arts. The same double-triangle representation from Figure $\mathbf{1}$ is shown here. In red text are the six types of two-way interactions between artforms. The directionality of the gray arrows in the top triangle implies that dance is often (though by no means always) performed to a musical beat, and that songs can be created by either setting pre-existing texts to music or by adding words to a pre-existing melody. The directionality of the gray arrows in the bottom triangle implies that visual forms - such as sets, props, costumes, and make-up - are generally created in the service of performance forms, such as theater and dance. Whereas most interactions involve simultaneous combinations of artforms, the interactions marked with asterisks (i.e., incidental music, and dance in verbal dramas) are those that tend to occur in alternation with one another.

objects. While some of these videos contain scenes with people in them, many of them do not. Some have sound (including music), while others are purely visual. Hence, this is a difficult form to characterize. We classify it as a visual-arts interaction with film, more so than one with theater. Another interesting interaction that is difficult to classify is the use of videos or animated films in performance works, such as operas or plays. For example, a production of Shostakovich's opera The Nose by the director and designer William Kentridge included a vast collage of both still images and animated images that appeared not only between the scenes of the opera but during the scenes as well.

\section{Dance/Visual Arts Interaction}

Everything mentioned in the last point about sets, props, costumes, make-up, venue, and multimedia applies here. A broader view of the visual arts, as developed in the twentieth century, incorporates a performance component to this branch of the arts. Hence, "performance art" takes the visual arts beyond the domain of static and inanimate images/objects and brings them into the realm of performance (Goldberg, 2011). We could list this as an interaction with either theater or dance (or both), but we include it with dance in the figure since it often occurs in a wordless manner, more reminiscent of dance than verbal theater.

\section{Music/Visual Arts Interaction}

The interactions between the visual arts and music are the least prominent among the interactions described in this section (although see the related discussion of music video above). Some multimedia installations displayed in museums not only have sound but include music. Background music is occasionally played ambiently throughout an entire exhibition space so as to give it a particular feel, say of a foreign culture whose artifacts are being exhibited. Outside of the context of museums, one occasionally finds images projected onto surfaces such as walls during musical concerts in concert halls. Music frequently occurs as an accompaniment to fireworks displays; composers such as Handel even created music specifically for such occasions. At the compositional level, there are many examples of paintings or sculptures that represent musicians and/or musical instruments (e.g., Picasso's many cubist guitars), as well as musical works that attempt to represent visual art works (e.g., Mussorgsky's Pictures at an Exhibition, based on paintings by Hartmann).

Having described these two-way interactions (and the threeway interaction of dancing while singing words), we would like to point out that these interactions can occur either simultaneously or sequentially. The vast majority of interactions shown in Figure 2 occur such that both artforms play out simultaneously. However, we mentioned previously that sung segments may occur as distinct from spoken segments in forms like musical theater, opéra comique, and Singspiel. Two additional examples of sequential interactions are marked with asterisks in the figure. First, in the case of incidental music, the music is interleaved with the dramatic segments of the play, rather than occurring simultaneously with them in the way that underscore 
does in films. Second, the dance segments found in theatrical forms like opera and musical theater are generally interleaved with the verbal parts of the drama, although they may occur simultaneously with sung parts in musical theater. Another interesting example to mention in this regard, although not shown in the figure, is recitative in opera, which differs from the principal segments of the opera in that the vocal style is much closer to speech than to standard singing. This type of sing-song speaking affords an audience the opportunity to acquire more narrative information about the plot than is generally possible in the sung segments. However, what is of importance here is that segments of recitative typically occur separately from those that are sung. In general, the two vocal styles are not blended within a single scene. The few examples of blending that come to mind are the Caucasian characters in Gershwin's opera Porgy and Bess who only speak but who interact with characters who sing, and Sprechstimme characters like Moses in Schoenberg's opera Moses und Aron who interact with characters who sing.

With this conception of artforms and their interactions in mind, we can now think about how to build a Gesamtkunstwerk. Figure 3 shows eight forms of the performing arts along the top. These are then classified with respect to their inclusion of four performance modalities: the speaking voice, the singing voice, instrumental music, and dance (and/or mime). The vertical arrows in the figure suggest that singing and dancing typically occur to the beat of instrumental music in these artforms. The dashed line for "music concert" implies that singing can have instrumental accompaniment, but that it can also be done all on its own, just the way that instrumental music can be done. At the extremes of the scheme are the least synthetic artforms of theater (speaking voice only) and mime (gesture only), although theater can involve incidental music, and mime can be performed to music, since it was initially conceived of as a form of dance (Hall, 2009). In the middle of the scheme sit the most synthetic forms. A major observation from this figure is that musical theater is the true Gesamtkunstwerk in Western art. Within the context of non-Western art, Peking opera shares all of the features of musical theater, making prominent use of dance and acrobatics. Richard Wagner, for all his aspirations to develop a total work of art, never included dances in his operas (although he mentions dance frequently in his writings, see Wagner, 1849), nor anything resembling standard speech. Hence, the Baroque operas that preceded Wagner (and that he despised) were probably closer to being total works of art than Wagner's own music-dramas.

While the focus of this article is on the performing arts, it should be mentioned that the field of "multimedia" presents its own type of synthesis of the arts (Costello, 2016), combining relatively static elements, such as still images and text, with dynamic audiovisual elements, such as video, animation, and music (Tan et al., 2013), and often doing so in a far more interactive manner than is generally the case in the performing arts. Finally, at a more elemental level, even still images like paintings can be seen as syntheses, integrating form, color, spatial organization, texture, implied depth, implied motion, symbolic content, and so forth.

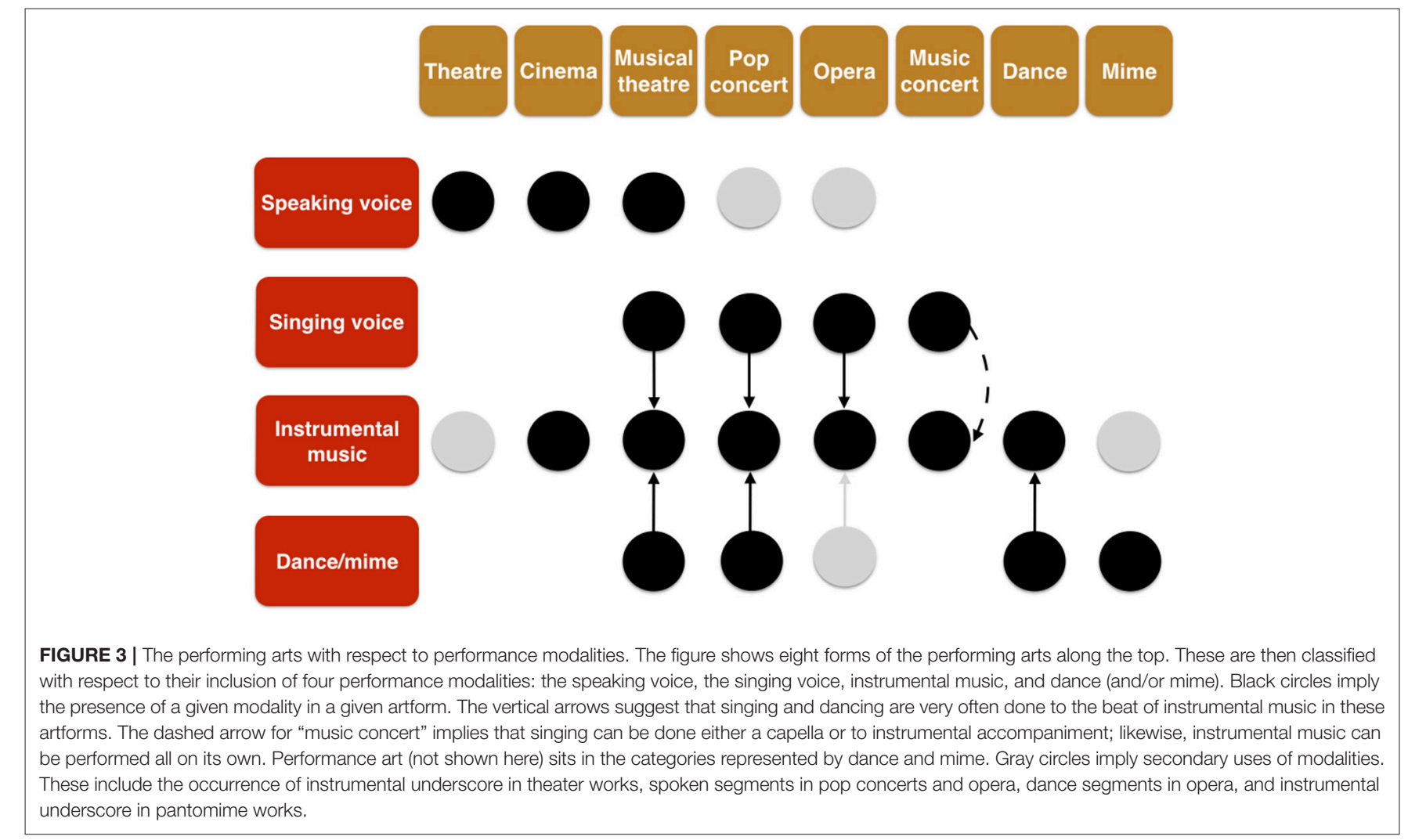




\section{CEREMONIAL RITUALS AS TOTAL WORKS OF ART}

The previous section established a recipe for building a total work of art by describing the ways in which the arts can be combined to generate synthetic forms. This has important ramifications for both historical accounts of the arts and the role of the arts in contemporary society. We contend that the nineteenth century notion of a Gesamtkunstwerk is neither new nor revolutionary. Ceremonial rituals in indigenous cultures across the world have manifested this practice ever since their inception, and have probably done so on a larger spatiotemporal scale and in a more participatory manner than theorists like Wagner could have imagined. In this section, we explore two complementary proposals, first that ceremonial rituals-and specifically religious ceremonial rituals - are so intimately connected with the arts that they can be conceived of as assemblages of the arts, and second, that these ceremonies were in fact the original GKW's in human societies. Figure 4 will serve as a guide for the discussion.

\section{Religion/Arts Co-evolution}

Since the start of the twenty-first century, there has been a surge of interest in the evolution and biology of religion (e.g., Barrett, 2000; Wilson, 2002; Bulbulia, 2004; Alcorta and Sosis, 2005; Johnson and Bering, 2006; Boyer and Bergstrom, 2008; Norenzayan and Shariff, 2008). Two principal issues dominate the discussions, first why people believe in supernatural beings and their agency, and second why people engage in elaborate group rituals that can last up to several days and that consume vast amounts of valuable resources, both material and personal. We can think of the first one as a cognitive issue and the second as behavioral.

Evolutionary psychologists have proposed a number of functional or causal mechanisms to explain the adaptive

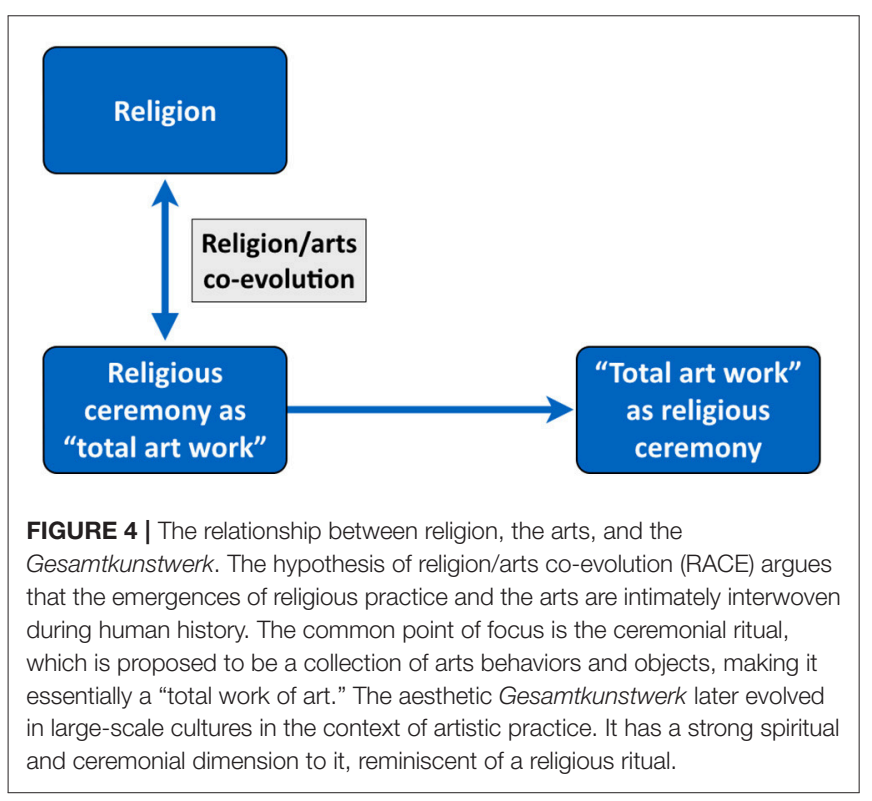

advantage of religious beliefs. Regarding belief in supernatural beings, it has been proposed that pro-social behaviors can be promoted by means of the moralizing force of such agents (e.g., Johnson, 2006, 2015). A supernatural being functions as a surrogate authority figure, especially one that operates when other humans are not around to observe and regulate one's behavior. People believe that they can avoid disfavor or punishment from the supernatural being by refraining from engaging in self-serving and antisocial behaviors and by acting kindly toward and cooperatively with other members of their social group. A belief in supernatural agency is essentially the application to physical phenomena of what Bruner (1986) calls the "narrative mode" of cognition. In the absence of physical theories to explain natural phenomena, people "narrativize" these natural events in terms of the intentionality of a supernatural being, with the implication being that these phenomena happen "for a reason," in the same way that human behavior is believed to happen (Bering, 2002).

While this causal type of explanation for belief in supernatural beings is specifically connected with religion, the behavioral explanation for religious group rituals is no different from that for non-religious group rituals: creating solidarity and coordination within a group, ultimately leading people to cooperate with one another and make personal sacrifices on the group's behalf (Sosis and Alcorta, 2003; Cohen et al., 2010; Whitehouse and Larman, 2014; Legare and Watson-Jones, 2015). Synchronization of movement and emotional expression through group rituals fosters a communitarian sense of belonging to the group and reduces barriers for cooperation with group members, not least with non-kin (Reddish et al., 2013; Launay et al., 2016). In particular, singing, dancing, and drumming all trigger endorphin release in contexts where merely listening to music or performing low-energy musical activities does not (Dunbar et al., 2012). This has led researchers to conclude that active participation in ritual musical performance and dancing is likely to stimulate these same neuropeptide systems and thereby give rise to the kinds of euphoric effects noted by Durkheim (1912/1995, his “collective effervescence"), Turner (1966), Roederer (1984), and others. These authors further note that these effects may play a particularly important role for humans in bonding social groups together (see also McNeill, 1995; Freeman, 2000; Dunbar, 2008).

Few evolutionary scholars have appreciated or even recognized that the arts in ceremonial rituals have been integral to religion as a behavioral and cognitive phenomenon. Examples of this omission include scholars such as Guthrie (1993), Hinde (1999), Pyysiäinen (2001), Boyer (2001), Atran (2002), McCauley and Lawson (2002), Kirkpatrick (2005), and Rossano (2010), although Alcorta and Sosis (2005) recognize the importance of the arts in ritual ceremonies for instilling cooperation and solidarity. We believe that this is far more an issue of neglect than one of disagreement. Hence, a major objective of the present article is to discuss this neglect and provide a framework for thinking about the religion/arts connection in a principled manner. Because of the inseparability of the two (religious practice and arts-like behavior), it is plausible to suggest that the arts-particularly those that take place in time, such as song, dance, and rhythmic or repetitive 
forms of movement or speech-arose during human history as components of ceremonial behavior, rather than as independent activities (Dissanayake, 1988, 1992).

In trying to connect the two major issues of belief and ritual in models of religion, there appears to be a significant gap. As mentioned above, non-religious communal behaviors that are synchronized and rhythmic seem to be quite efficacious at creating group cohesion (Cohen et al., 2010; Reddish et al., 2013; Launay et al., 2016), without requiring supernatural belief. Likewise, belief in supernatural beings for many people, even in contemporary society, can operate effectively at the personal level, without requiring group rituals. So, what is the missing link that makes religious belief something that requires communal rituals, and that makes ritual into a manifestation and reinforcer of religious belief? We suggest that it is the arts. We propose that the arts provide an emotionally-felt and transcendent means of establishing contact with supernatural beings during communal ceremonial rituals. Such contact can be as simple as drawing the being's attention to oneself, all the way to the expressions of request, penitence, praise, etc., that underlie worship in large-scale religions (Ladd and Spilka, 2002; Spilka et al., 2003; Poloma and Lee, 2011).

Dissanayake's (1988, 2009) concept of "artification" (or "making special") is relevant here. The kinds of arts behaviors that are found in religious rituals across cultures-from incantations to drumming to gestural displays to elaborate regalia to body ornamentation to incense-are ways of making the occasion (with its wish, desire, plea, or need) special and thus distinct from the mundane actions and communications among humans that occur in everyday settings. In addition, they are ways of making oneself special (self-artification), thereby presenting oneself appropriately to a transcendent being. In religious ceremonial rituals, both the communicator and the communication process become strongly artified. This investment in extravagance demonstrates that the performers "really mean it," that is, that the topic of the ritual is an important and communally-shared matter, for example subsistence, safety, health, prosperity, fertility, or transitioning to a new stage of life.

Hence, arts-permeated religious ceremonial rituals are intended to attract and establish contact with supernatural beings, creating a sanctified realm of interaction distinct from ordinary social interactions. These manifestations are meant to influence the actions of these supernatural beings toward particular individuals and/or the social group as a whole. The arts, as manifested in ceremonial rituals, are essentially acts of persuasion. This idea is consistent with work on Western religions showing that worship aims to place the worshiper in a positive light with respect to gods, such that requests of gods are accompanied by conciliatory expressions of praise, thanks, and confession (Ladd and Spilka, 2002; Spilka et al., 2003; Poloma and Lee, 2011). It needs to be pointed out that not all forms of religious behavior need be extravagant. Our ideas apply first and foremost to communal ceremonial rituals, where the presence of arts behaviors and objects is quite compelling. However, there are forms of individual penitence (fasting, mortification of the flesh), sacrifice, and personal prayer, including meditative prayer
(Poloma and Pendelton, 1989), that may be quite ascetic and that may even aspire toward a renunciation of material objects. However, these behaviors, in general, are still "ritualized" in the ethological sense (Dissanayake, 1988, 1992), as described in the next paragraph.

Numerous theorists have written about the nature of ceremonial rituals from an anthropological perspective, especially in traditional societies (Durkheim, 1912/1995; Turner, 1966; Schechner, 1974, 1985; Tambiah, 1979; Dissanayake, 1988, 1992, 2017; Rappaport, 1999). Ceremonial processes are highly ritualized, involving particular locations and times of day, and employing a large degree of repetitive action. This is seen especially with body movements and vocal chants. The process of "ritualization" when applied to animal courtship and territorial behaviors refers to particular changes or "operations" that make the activity prominent, distinctive, and unambiguous (Smith, 1977; Eibl-Eibesfeldt, 1989). Unlike the original instrumental or ordinary precursor-behavior that inspired them, ritualized movements and sounds become "extraordinary" and thus attract attention (Dissanayake, 1988). They typically become (a) simplified or stereotyped (formalized), and (b) repeated rhythmically, often with a "typical" intensity Morris (1957), that is, with a characteristic regularity of pace. The signals are frequently (c) exaggerated in time and space, and (d) are further emphasized or elaborated by the development of special colors or anatomical features. These components are polymodal in that they can occur visually, vocally, or gesturally in both space and time. These well-described characteristics of the ritualization process in animals are also distinct and conspicuous in human ritual ceremonies and are characteristic of the arts.

In traditional cultures, human rituals are highly participative and communal, blurring the standard Western distinction between creators, performers, and spectators. The "persuasion" effect of the arts during ceremonial rituals has an impact not only on the supernatural beings being honored and entreated but also on the participants themselves. Arts-saturated rituals act as emotional reinforcers of the belief systems being communicated during the ritual, ultimately supporting a sense of consensus among members of the group with respect to these belief systems. Interestingly, compared to the neophilia of modern art, ritual activities are highly conservative, since they are driven by a social need to uphold and perpetuate tradition, serving both to respect the actions of ancestors and to maintain group identity (Coe, 2003). Because of their critical importance to the life of a social group, rituals show very slow rates of change compared to nonritual behaviors and products, making them among the most persistent features of any culture, whether that be a large-scale culture or an indigenous culture. Pop music may change by the season, but religious music can persist for centuries if not millennia.

Although a scientific worldview would be skeptical of the idea that artified rituals themselves are effective at resolving the vital pragmatic problems that inspire them, for example those related to successful hunting or influencing weather patterns, we consider them valuable in that they address and satisfy evolved emotional needs in human psychology. Rituals, through their characteristic operations, create and reinforce 
emotionally-satisfying and psychologically-necessary feelings of mutuality and intimacy with other people (Bowlby, 1946; Miller and Rodgers, 2001; Dissanayake, 2011), as well as a sense of belonging to a group (Hinde, 1974; Baumeister and Leary, 1995; Dissanayake, 2000; Gratier and Apter-Danon, 2009). They coordinate and unify group members in a reassuring feeling of "oneheartedness" that provides an affective foundation for collective and cooperative behaviors that can be both risky and costly. They promote seven social functions that, in the realm of musical participation, have been referred to as the Seven C's, namely contact, social cognition, copathy (being empathically affected so that inter-individual emotional states become more homogeneous), communication, coordination, cooperation, and cohesion (Koelsch, 2013), ultimately leading to a sense of community (an Eighth C).

Overall, we have proposed here a model of religion/arts co-evolution (RACE). The arts evolved in the context of religion, and religion evolved in the context of arts-based group rituals, where the two interfaced most strongly at the level of ceremonial rituals. The arts most likely arose in human history as communicative components of propitiary and supplicatory group rituals, rather than as independentlyevolved activities, hence making the unification of religion and the arts a natural coupling. Evolutionary theorists of religion regularly make mention of group rituals, but not of their pervasive arts components. Secular group rituals might have been sufficient on their own for promoting the survival needs of group living, but religious rituals redirect the focus toward a moral force that is higher, stronger, and more effective than any single member of the group (Johnson, 2015), which is not the case in secular rituals. For this reason, they are probably more efficient at engendering coordination strength, group identity, and interpersonal cooperation. A large investment is made by group members in establishing this specialized mode of contact with supernatural powers, with the hope of achieving desirable outcomes and of alleviating adverse conditions.

Emile Durkheim's classic book The Elementary Forms of Religious Life (1912/1995) presents a wide-ranging early analysis of religious rituals in indigenous cultures. Importantly for our purposes, Durkheim's perspective of ritual is grounded in a vast fusion of artforms, one that includes not just singing and dancing, but face painting, body decoration, mime, costume, drawing, oral storytelling, and the theatrical conveyance of the myths and prospects of a culture through "sacred drama". Watts Miller (2013) refers to this fusion as Durkheim's "total aesthetics." Therefore, Durkheim might have been the earliest thinker to propose that religious ceremonial rituals served as the ancestral roots of GKW's. Such rituals, through their promotion of group assembly and communal participation, bind people together via a process that Durkheim calls collective effervescence, a process that is strongly linked to the effects of the arts components of these rituals.

Finally, a similar perspective can be found in Richard Schechner's writings about the emergence of theater from religious ritual, and even the reverse development of ritual from theater. While Schechner (1974) describes the multiarts nature of rituals-combining dance, music, drama, and elaborate body ornamentation-his principal focus is on how the purposeful efficacy of rituals becomes transformed into the entertainment function of theater, an inter-relationship that he refers to as the "efficacy/entertainment braid." Hence, his hypothesis is less a religion/arts model as an historical account of how cultural practices have changed from being ritual-centric to becoming entertainment-centric. For example, in analyzing European history, he states that "[T]he late medieval period was dominated by efficacious performances: church services, court ceremonies, moralities, pageants. In the early Renaissance these began to decline and popular entertainments, always present, gained, finally becoming dominant in the form of the public theaters of the Elizabethan period" (Schechner, 1974, p. 470).

\section{Ceremonies as Collections of Arts Behaviors}

The major observation that emerges from the RACE hypothesis is that ceremonial rituals are so filled with arts behaviors and objects that if one were to take away these arts components one by one, there would be little that would remain with respect to group behaviors and shared symbolic objects. (Of course, individual-level processes would remain, such as cognitive and emotional connections with supernatural beings). This leads us to postulate that religious ceremonial rituals, at the behavioral and material levels, can be considered as being reducible to collections of arts behaviors and objects. Table 1 presents a general enumeration of the types of arts-related behaviors and objects that are found in some or all ceremonial rituals in world cultures, covering music, dance, language use, drama, the visual arts (regalia, masks, artifacts, body ornamentation, etc.), and the chemical arts (such as materials that are smelled or consumed); these artforms can readily interact to form blends, either simultaneously or sequentially (Figures 2, 3). It is difficult to conceive of religious ceremonial rituals without these behaviors and implements. Without these "transfigurations of the commonplace" (Danto, 1981), it is hard to imagine what would constitute a ceremony. The more that one looks toward indigenous cultures, the more pervasive and necessary these artsrelated elements seem to be in the performance of group rituals. The arts are not ancillary add-ons, but are instead essential components of the ritual. In fact, an absence of these behaviors or their improper execution can contaminate or invalidate the ritual, with potentially severe repercussions for those involved, including death (Liénard and Boyer, 2006). Overall, we feel that the ceremonies-as-arts perspective provides compelling support for the RACE model.

\section{The Ceremonial Ritual as the Precursor of the Total Work of Art}

To now bring the argument of this article full circle, we propose that long before aesthetic theorists had devised the notion of a Gesamtkunstwerk, ceremonial rituals in indigenous cultures had for millennia been syntheses of the arts on a similar scale and of a similar scope to GKW's. In other words, ceremonial 
TABLE 1 | Artforms found in religious ceremonial rituals.

\begin{tabular}{ll}
\hline Music & $\begin{array}{l}\text { Chanting; drumming; playing melodic instruments } \\
\text { (e.g., flutes) } \\
\text { Dance }\end{array}$ \\
& Dancing; pantomime; gestural displays (e.g., \\
& Prayers; scriptures; incantations; song texts; \\
Language & sermons \\
Drama & Re-enactment rituals; storytelling; possession; \\
& trance \\
Visual arts & Ritual objects; regalia; masks; make-up; body \\
& modification \\
Chemical arts & Incense; consuming or offering special foods (e.g., a \\
& sacrifice); psychotropic substances
\end{tabular}

rituals are the historical precursor to what aesthetic philosophers would later call GKW's in artistic practice. The complementary idea, as shown on the right side of Figure 4, is that GKW's themselves came to adopt quasi-religious practices so as to become ceremonies in their own right. Wagner's music-dramas are the most celebrated example of this (Smith, 2007). The GKW would take place in a grandiose setting akin to a temple of the arts, to which the spectators would make a pilgrimage. The work would deal with spiritual and mythological themes that would transport the work out of the mundane and technological world of today and bring the audience back to its cultural roots. The work would combine theater, music, poetic language, and elaborate visuals into a "pseudo-organic totality" whose performance would occur over a time span much longer than a standard concert or theater performance. The experience would be transformative for those in attendance, rather than being a form of entertainment and diversion. It would be something along the lines of a religious experience, a route to redemption through the arts. This notion of arts-as-religion came to permeate much thinking about the arts in the late nineteenth and early twentieth centuries and is not altogether absent in our times. "Great art," and indeed participation in the arts in general, is still thought to nourish people's spiritual side and improve their

\section{REFERENCES}

Alcorta, C. S., and Sosis, R. (2005). Ritual, emotion, and sacred symbols: the evolution of religion as an adaptive complex. Hum. Nat. 16, 323-335. doi: $10.1007 / \mathrm{s} 12110-005-1014-3$

Atran, S. (2002). In Gods We Trust: The Evolutionary Landscape of Religion. New York, NY: Oxford University Press.

Barrett, J. L. (2000). Exploring the natural foundation of religion. Trends Cogn. Sci. 4, 29-34. doi: 10.1016/S1364-6613(99)01419-9

Baumeister, R. F., and Leary, M. R. (1995). The need to belong: desire for interpersonal attachments as a fundamental human motivation. Psychol. Bull. 117, 497-529. doi: 10.1037/0033-2909.117. 3.497

Bering, J. M. (2002). The existential theory of mind. Rev. Gen. Psychol. 6, 3-24. doi: $10.1037 / 1089-2680.6 .1 .3$

Bowlby, J. (1946). Psychology and democracy. Polit. Q. 17, 61-75. doi: 10.1111/j.1467-923X.1946.tb01028.x well-being. This is one of the planks that motivates the use of individual arts for therapeutic purposes, including therapies based on music, dance, writing, verbal expression, role playing, and painting (Gladding, 2011). In addition, in the late twentieth century, there was a notable impetus to use the arts as a means of promoting learning in the classroom. In some respects, we haven't moved very far away from Schiller's 1794 notion of aesthetic education (Smith, 2007).

\section{CONCLUSIONS}

The nineteenth century concept of a Gesamtkunstwerk has deep evolutionary roots in religious practice across cultures, as suggested by anthropological and ethological analyses of the arts. Ceremonial rituals, especially the type that permeate religious practice, can be considered essentially as assemblages of arts behaviors and objects, making them the precursor of what would later be called the total work of art in aesthetic practice, with its own quasi-religious flavor. We have presented a framework for describing how a total work of art can be constructed by identifying the manners in which the arts can combine, involving both simultaneous and sequential interactions between artforms. Such combinations are seen ubiquitously not only in art works but in ceremonial rituals of all kinds, suggesting a strong coevolutionary relationship between religion and the arts.

\section{AUTHOR CONTRIBUTIONS}

Both SB and ED conceived of the ideas of this paper and wrote the manuscript.

\section{ACKNOWLEDGMENTS}

This work was supported by a grant from the Social Sciences and Humanities Research Council (SSHRC) of Canada to SB. We thank students in SB's undergraduate class The Science of Performance for critical commentary on the manuscript, and appreciate the helpful suggestions of two reviewers.

Boyer, P. (2001). Religion Explained: Evolutionary Origins of Religious Thought. New York, NY: Basic Books.

Boyer, P., and Bergstrom, B. (2008). Evolutionary perspectives on religion. Annu. Rev. Anthropol. 37, 111-130. doi: 10.1146/annurev.anthro.37.081407.085201

Bruner, J. (1986). Actual Minds, Possible Worlds. Cambridge, MA: Harvard University Press.

Bulbulia, J. (2004). The cognitive and evolutionary psychology of religion. Biol. Philos. 19, 655-686. doi: 10.1007/s10539-005-5568-6

Coe, K. (2003). The Ancestress Hypothesis: Visual Art as Adaptation. New Brunswick, NJ: Rutgers University Press.

Cohen, E. E., Ejsmond-Frey, R., Knight, N., and Dunbar, R. I. (2010). Rowers' high: behavioural synchrony is correlated with elevated pain thresholds. Biol. Lett. 6, 106-108. doi: 10.1098/rsbl.2009.0670

Costello, V. (2016). Multimedia Foundations: Core Concepts for Digital Design, 2nd Edn. New York, NY: Routledge.

Danto, A. (1981). The Transfiguration of the Commonplace. Cambridge, MA: Harvard University Press. 
Dissanayake, E. (1988). What is Art For? Seattle, WA: University of Washington Press.

Dissanayake, E. (1992). Homo Aestheticus: Where Art Comes From and Why. Seattle, WA: University of Washington Press.

Dissanayake, E. (2000). Art and Intimacy: How the Arts Began. Seattle, WA: University of Washington Press.

Dissanayake, E. (2009). The artification hypothesis and its relevance to cognitive science, evolutionary aesthetics, and neuroaesthetics. Cogn. Semiot. 5, 148-173. doi: 10.1515/cogsem.2009.5.fall2009.136

Dissanayake, E. (2011). Prelinguistic and preliterate substrates of poetic narrative. Poet. Today 32, 55-79. doi: 10.1215/03335372-1188185

Dissanayake, E. (2017). "From play and ritualisation to ritual and its arts: sources of Upper Pleistocene ritual practices in Lower Middle Pleistocene ritualised and play behaviours in ancestral hominins," in Ritual, Play and Belief in Early Human Societies, eds C. Renfrew, I. Morley, and M. Boyd (Cambridge: Cambridge University Press), 87-98.

Dunbar, R. I. M. (2008). Mind the bonding gap: or why humans aren't just great apes. Proc. Br. Acad. 154, 403-423. doi: $10.5871 /$ bacad/9780197264355.003.0015

Dunbar, R. I., Kaskatis, K., MacDonald, I., and Barra, V. (2012). Performance of music elevates pain threshold and positive affect: implications for the evolutionary function of music. Evol. Psychol. 10, 688-702. doi: $10.1177 / 147470491201000403$

Durkheim, E. (1912/1995). The Elementary Forms of Religious Life. Transl. by K. E. Fields. New York, NY: The Free Press.

Eibl-Eibesfeldt, L. (1989). Human Ethology. Transl. by P. Wiessner-Larsen and A. Heunemann.New York, NY: Aldine de Gruyter.

Elkins, J. (1999). The Domain of Images. New York, NY: Cornell University Press.

Freeman, W. J. (2000). “A neurobiological role of music in social bonding," in The Origins of Music, eds N. Wallin, B. Merker, and S. Brown (Cambridge, MA: MIT Press), 411-424.

Gladding, S. T. (2011). The Creative Arts in Counseling, 4th Edn. Alexandria, VA: American Counseling Association.

Goldberg, R. (2011). Performance Art: From Futurism to the Present, 3rd Edn. London: Thames \& Hudson.

Gratier, M., and Apter-Danon, G. (2009). “The improvised musicality of belonging: repetition and variation in mother-infant vocal interaction," in Communicative Musicality: Exploring the Basis of Human Companionship, eds S. Malloch and C. Trevarthen (Oxford: Oxford University Press), 301-327.

Guthrie, S. E. (1993). Faces in the Clouds: A New Theory of Religion. Oxford: Oxford University Press.

Hall, E. (2009). "Introduction: Pantomime, a lost chord of ancient culture," in New Directions in Ancient Pantomime, eds E. Hall and R. Wyles (Oxford: Oxford University Press), 1-40.

Hinde, R. A. (1974). Biological Bases of Human Social Behaviour. New York, NY: McGraw-Hill.

Hinde, R. A. (1999). Why Gods Persist: A Scientific Approach to Religion. London: Routledge,

Johnson, D. (2015). God is Watching You: How the Fear of God Makes Us Human. Oxford: Oxford University Press.

Johnson, D., and Bering, J. (2006). Hand of God, mind of man: punishment and cognition in the evolution of cooperation. Evol. Psychol. 4, 219-233. doi: 10.1177/147470490600400119

Johnson, D. D. (2006). God's punishment and public goods: a test of the supernatural punishment hypothesis in 186 world cultures. Hum. Nat. 16, 410-444. doi: 10.1007/s12110-005-1017-0

Kimmel, M., and Preuschl, E. (2016). "Dynamic coordination patterns in tango argentino: a cross-fertilization of subjective explication methods and motion capture," in Dance Notations and Robot Motion, eds J. L. Laumond and N. Abe (New York, NY: Springer), 209-235.

Kirkpatrick, L. A. (2005). Attachment, Evolution, and the Psychology of Religion. New York, NY: Guilford.

Koelsch, S. (2013). Towards a neural basis of music-evoked emotions. Trends Cogn. Sci. 14, 131-137. doi: 10.1016/j.tics.2010.01.002

Ladd, K. L., and Spilka, B. (2002). Inward, outward, and upward: cognitive aspects of prayer. J. Sci. Study Relig. 41, 475-484. doi: 10.1111/1468-5906.00131
Launay, J., Tarr, B., and Dunbar, R. (2016). Synchrony as an adaptive mechanism for large-scale human social bonding. Ethology 122, 779-789. doi: 10.1111/eth. 12528

Legare, C. H., and Watson-Jones, R. E. (2015). "The evolution and ontogeny of ritual," in The Handbook of Evolutionary Psychology, ed D. M. Buss (Hoboken, NJ: Wiley Sons), 829-847.

Liénard, P., and Boyer, P. (2006). Whence collective rituals? A cultural selection model of ritualized behavior. Am. Anthropol. 108, 814-827. doi: 10.1525/aa.2006.108. 4.814

McCauley, R. N., and Lawson, E. T. (2002). Bringing Ritual to Mind. New York, NY: Cambridge University Press.

McNeill, W. H. (1995). Keeping Together in Time: Dance and Drill in Human History. Cambridge, MA: Harvard University Press.

Miller, W. B., and Rodgers, J. L. (2001). The Ontogeny of Human Bonding Systems: Evolutionary Origins, Neural Bases, and Psychological Manifestations. Boston, MA; Dordrecht: Kluwer Academic Publishers.

Morris, D. (1957). "Typical intensity" and its relation to the problem of ritualization. Behaviour 11, 1-2.

Norenzayan, A., and Shariff, A. F. (2008). The origin and evolution of religious prosociality. Science 322, 58-62. doi: 10.1126/science.1158757

Patel, A. D. (2008). Music, Language and the Brain. Oxford: Oxford University Press.

Poloma, M. M., and Lee, M. T. (2011). From prayer activities to receptive prayer: godly love and the knowledge that surpasses understanding. J. Psychol. Theol. 39, 143-154. doi: 10.1177/0091647111039 00205

Poloma, M. M., and Pendelton, B. F. (1989). Exploring types of prayer and quality of life: a research note. Rev. Relig. Res. 31, 46-53. doi: 10.2307/35 11023

Pyysiäinen, I. (2001). How Religion Works: Towards a New Cognitive Science of Religion. Leiden: Brill.

Rappaport, R. A. (1999). Ritual and Religion in the Making of Humanity. Cambridge: Cambridge University Press.

Reddish, P., Fischer, R., and Bulbulia, J. (2013). Let's dance together: synchrony, shared intentionality and cooperation. PLoS ONE 8:e71182. doi: 10.1371/journal.pone.0071182

Roederer, J. (1984). The search for a survival value of music. Music Percept. 1, 350-356. doi: 10.2307/40285265

Rossano, M. (2010). Supernatural Selection: How Religion Evolved. Oxford: Oxford University Press.

Schechner, R. (1974). From ritual to theatre and back: the structure/process of the efficacy-entertainment dyad. Educ. Theat. J. 26, 455-481. doi: 10.2307/32 06608

Schechner, R. (1985). Between Theater and Anthropology. Philadelphia, PA: University of Pennsylvania Press.

Smith, M. W. (2007). The Total Work of Art: From Bayreuth to Cyberspace. New York, NY: Routledge.

Smith, W. (1977). The Behavior of Communicating: An Evolutionary Approach. Cambridge, MA: Harvard University Press.

Sosis, R., and Alcorta, C. S. (2003). Signaling, solidarity and the sacred: the evolution of religious behavior. Evol. Anthropol. 12, 264-274. doi: 10.1002/evan.10120

Spilka, B., Hood, R. W. Jr., Hunsberger, B., and Gorsuch, R. L. (2003). The Psychology of Religion: An Empirical Approach, 3rd Edn. New York, NY: Guilford.

Tambiah, S. J. (1979). A performative approach to ritual. Proc. Br. Acad. 65, 113-169.

Tan, S.-L., Cohen, A. J., Lipscomb, S. D., and Kendal, R. A. (eds.). (2013). The Psychology of Music in Multimedia. Oxford: Oxford University Press.

Turner, V. (1966). The Ritual Process: Structure and Anti-Structure. Ithaca: Cornell University Press.

von Scheve, C., and Salmella, M. (eds.). (2014). Collective Emotions: Perspectives from Psychology, Philosophy, and Sociology. Oxford: Oxford University Press.

Wagner, R. (1849). The Artwork of the Future. Transl. by W. A. Ellis. Lincoln, NB: University of Nebraska Press. 
Watts Miller, W. (2013). "Total aesthetics: art and the elemental forms," in Durkheim, the Durkheimians, and the Arts, eds A. Riley, W. S. F. Pickering, and W. Watts Miller (New York, NY: Berghahn Books), 16-42.

Whitehouse, H., and Larman, J. A. (2014). The ties that bind us: ritual, fusion, and identification. Curr. Anthropol. 55, 674-695. doi: 10.1086/678698

Wilson, D. S. (2002). Darwin's Cathedral: Evolution, Religion, and the Nature of Society. Chicago, IL: University of Chicago Press.

Yuan, Y., Major-Girardin, J., and Brown, S. (in press). Storytelling is intrinsically mentalistic: an fMRI study of narrative production across modalities. J. Cogn. Neurosci.
Conflict of Interest Statement: The authors declare that the research was conducted in the absence of any commercial or financial relationships that could be construed as a potential conflict of interest.

Copyright $\odot 2018$ Brown and Dissanayake. This is an open-access article distributed under the terms of the Creative Commons Attribution License (CC BY). The use, distribution or reproduction in other forums is permitted, provided the original author(s) and the copyright owner are credited and that the original publication in this journal is cited, in accordance with accepted academic practice. No use, distribution or reproduction is permitted which does not comply with these terms. 